\title{
Temperature-derived potential for the establishment of phlebotomine sandflies and visceral leishmaniasis in Germany
}

\author{
Dominik Fischer, Stephanie M. Thomas, Carl Beierkuhnlein \\ Department of Biogeography, University of Bayreuth, Universitätsstrasse 30, D-95447 Bayreuth, Germany
}

\begin{abstract}
Climate change is expected to manifest in the shift of organisms to regions where they were not present in the past, potentially entailing previously unseen biological risks. However, studies evaluating these future trends are scarce. Here, an important group of vectors (sandflies) and the pathogen transmitted (Leishmania infantum complex) causing the infectious disease visceral leishmaniasis is investigated, focussing on potential establishment in Germany during the $21^{\text {st }}$ century. As the most important habitat factor, temperature requirements of pathogen and vector were derived from the literature and compared with recent climate records - provided by worldclim - and climate change scenarios. Climate data from the Regional Climate Model REMO were obtained and averaged over the time periods 20112040, 2041-2070 and 2071-2100. Projected temperature changes (based on the A1B and A2 scenarios) were correlated with the constraints of vector and pathogen. Simulated potentially suitable habitat areas for vector and pathogen were merged to generate a temperature-derived risk map of visceral leishmaniasis. Temperature conditions seem to become suitable for the vector across large swaths of Germany. Nevertheless, temperature constraints for the pathogen may defer the establishment of the parasitic disease, particularly during the first half of the $21^{\text {st }}$ century. Long-lasting epidemics of visceral leishmaniasis are therefore not expected in Germany during the next few decades, although during extremely warm years an increase in autochthonous cases of leishmaniasis may occur. The southwest (Upper Rhine Valley) and west (Cologne Bight) of Germany are identified as risk areas. The time of potential establishment and corresponding rise in biological risk varies between scenarios, due to differences in the predicted rate of temperature increase.
\end{abstract}

Keywords: climate change, global warming, Europe, leishmaniosis, kala-azar, Phlebotomus, vector-borne disease.

\section{Introduction}

Regional climate change has been linked with potential impacts on human health in various ways (Patz et al., 2005), such as those health-related problems and hazards (e.g. water shortages or floods) associated with an expected increase in extreme climatic conditions including heat waves, drought and heavy rainfall (Jentsch and Beierkuhnlein, 2008). Besides these meteorological

Corresponding author:

Dominik Fischer

Department of Biogeography, University of Bayreuth

Universitätsstrasse 30, D-95447 Bayreuth, Germany

Tel. +49 2155 2307; Fax +49 21552315

E-mail: dominik.fischer@uni-bayreuth.de stress situations with direct impacts on human and animal health, organism and ecosystem responses to climate change are also expected to entail indirect impacts on public health (Fischer et al., 2010).

As a prominent example, vector-borne infectious diseases may spread from subtropical or tropical regions to higher latitudes and altitudes (e.g. Shope, 1991; Fischer et al., 2009). Infectious diseases such as malaria or dengue occur on several continents. Increasing human population density, global trade and climatic changes are all likely connected to the increased numbers of reported cases (Sutherst, 2004).

However, as people are unfamiliar with diseases that were previously confined to specific regions, their potential expansion has been widely neglected or even ignored. The documented spread of leish- 
maniasis (Shaw, 2007; Maroli et al., 2008) is one such problem demanding more attention in terms of both science and policy (Dujardin et al., 2008). Formerly restricted to South America, India, the Middle East and the Mediterranean, the annual incidence of leishmaniasis is approximately 2 million cases, while about 350 million people reside temporarily or permanently in leishmaniasis risk areas (Reithinger and Dujardin, 2007). Pathogens belonging to the Leishmania infantum complex (L. infantum complex; endemic in Europe) or Leishmania donovani complex (endemic in Asia) both cause visceral leishmaniasis in humans and animals (Gramiccia and Gradoni, 2005). In Europe, sandflies of the genus Phlebotomus serve as vectors, transmitting these obligate intracellular parasites to new hosts where they infect internal organs such as the liver and spleen (Neuber, 2008). Phlebotomus spp. are located in rural as well as urban environments in close proximity to humans and their domestic animals, largely dogs which are the main reservoir of the L. infantum complex (Camargo and Langoni, 2006). These small insects (length $=2-3$ $\mathrm{mm})$ are strongly dependent on specific environmental conditions (e.g. Cross and Hyams, 1996; Aspoeck et al., 2008). The first documented sandfly catches (Phlebotomus mascittii and P. perniciosus) in Germany came from the south-west on the border with France (Naucke and Pesson, 2000; Naucke et al., 2008). Conceivably, the species had already reached central Europe from Mediterranean refugial areas during the Holocene optimum (approximately 6,500 years ago), survived in very small areas and due to global warming is now spreading (Aspoeck, 2008; Aspoeck et al., 2008).

Until now, most cases of infection reported from Germany have been allochthonous, associated with imported pets (i.e. dogs), especially from the Mediterranean region, and travelling humans (Harms et al., 2003; Weitzel et al., 2005). However, Bogdan et al. (2001) reported the first case of autochthonous visceral leishmaniasis in a German child, while the number of autochthonous cases of canine leishmaniasis has also increased. In total, 11 cases with assumed autochthonous origins have been diagnosed in humans and animals in Germany (Naucke et al., 2008). This is the ominous "smoking gun" suggesting that infected sandflies must be present at least periodically in Germany.

Spatio-temporal models may become crucial components of leishmaniasis risk analyses (Ready, 2008). Compared with other diseases and their vectors, only a few studies have investigated leishmaniasis and sandflies with an environmental-climatic focus via species distribution models (e.g. Peterson and Shaw, 2003; Nieto et al., 2006; Chamaille et al., 2010), geographical information system (GIS) and remote sensing techniques (Rossi et al., 2007). Aspoeck et al. (2007) estimated the risk of autochthonous leishmaniasis in Austria, identifying temperature as the most important variable.

The northern limit of sandflies in Europe is closely related to the $10{ }^{\circ} \mathrm{C}$ annual mean temperature isotherm (Naucke, 2007; Lozán et al., 2008). Sandflies require an average monthly temperature of at least $20{ }^{\circ} \mathrm{C}$ during the warmest month, which corresponds with their activity phase (WHO, 1984). Winter temperatures may not be as crucial to their occurrence, since diapause enables overwintering in tunnels and holes (Killick-Kendrick and KillickKendrick, 1987).

Evidence suggests that the L. infantum complex is prevalent only in areas with average temperatures ranging between $5-10{ }^{\circ} \mathrm{C}$ during the coldest month and $20-30{ }^{\circ} \mathrm{C}$ during the warmest month (Kuhn, 1999). Based on the detected constraints imposed on vectors and pathogens by temperature, potential future risk zones can be identified.

Until now, no study has investigated the future risk of visceral leishmaniasis for regions north of the Alps. Regarding these known temperature requirements for vector and pathogen suitability in the light of projected climate change for Germany during the $21^{\text {st }}$ century, the following questions arise:

(i) When will climatic vector requirements be fulfilled?

(ii) When will climatic pathogen requirements be fulfilled? 
(iii) Which specific regions will be exposed to this novel threat?

\section{Materials and methods}

\section{Climatic data}

Present-day vector and pathogen temperature constraints (annual mean temperature and temperature of the warmest and coldest months) were established at 5 arc-minutes resolution from data published in Hijmans et al. (2005) for recent climatic conditions in Germany.

Projected temperature change during the $21^{\text {st }}$ century was derived from the regional climate model REMO (UBA project, datastream 3), which is driven by the global climate model ECHAM5 (Jacob, 2008). REMO also integrates regional details through the use of highly resolved dynamic downscaling and as a result is able to project climatic change at the regional scale of Central Europe more precisely (Déqué et al., 2007). Regional climate change simulations are therefore more powerful tools for the detection of future risks of climate-sensitive vector-borne diseases (Jacob, 2008; Fischer et al., 2010).

The climate change simulations used in this study were based on theoretical IPCC (2007) emission scenarios for greenhouse gases. The A1B scenario is characterised by rapid economic growth and technological change towards the balanced use of all energy resources, while the A2 scenario projects regionally-oriented economic development and diversification of energy use. Both of these selected scenarios are accepted to represent realistic potential developments.

Following typical climatological procedure, projected monthly and annual mean temperatures from REMO were averaged over 30-year intervals to reduce uncertainty in deriving climatic trends. Periods considered in the analysis of projected trends were: 2011-2040, 2041-2070 and 20712100. Analysis of each scenario was carried out separately. Projected values of annual mean temperature, selected warmest and coldest month were taken for further analysis.

Current and projected temperature data were incorporated at a spatial resolution of $6 \mathrm{~km}$, in order to overlay and accurately compare results for recent and projected conditions. The area of Germany was then extracted for analysis.

The climatic data provided by Hijmans et al. (2005) were already available as raster data, but projected climatic data derived from REMO had to be prepared using climate data operators (CDO) codes, before finally being transformed to raster format for further analysis in ArcGIS (version 9.1).

Temperature suitability for organisms and risk classes of visceral leishmaniasis

First, four temperature-derived suitability classes for vector and pathogen were established separately, taking into account the overlay of their temperature constraints (Table 1). Classes were generated from the comparison of current and projected temperature conditions with vector and pathogen constraints. The results produced represent temperature-derived areas in Germany suitable for Phlebotomus spp. (Fig. 1) and the L. infantum complex (Fig. 2).

Classified habitat suitability data for vector and pathogen were then combined to generate temperature-related risk classes for the establishment of visceral leishmaniasis. By analysing the fulfilment of vector and pathogen requirements under current conditions and throughout the time periods of both scenarios, risk was classified on a range from excludable to likely (Table 1 ).

By overlaying the classified raster cells of each single map, calculated risk classes of visceral leishmaniasis for each individual time period and scenario were then compared with each other. This was done in order to identify significant temporal trends and differences between scenarios. The specific area of every leishmaniasis risk class was also calculated for each individual time period and scenario. These analyses were carried out in ArcGIS. 
Table 1. Classification of current and projected temperature conditions with regard to vector and pathogen requirements. Annual mean temperature of at least $10^{\circ} \mathrm{C}$ (Naucke, 2007; Lozán et al., 2008) and average monthly temperature of more than $20^{\circ} \mathrm{C}$ during the warmest month (WHO, 1984) are considered to be suitable for the vector. Pathogen suitability classes are based on the fulfillment of temperature requirements during the coldest month $\left(5-10{ }^{\circ} \mathrm{C}\right)$ and warmest month $(20-30$ $\left.{ }^{\circ} \mathrm{C}\right)$ (Kuhn, 1999). More than one combination of vector and pathogen suitability classes resulting in one risk class for the disease establishment are possible. Dotted lines separate the possible combination of one pathogen suitability class with two vector suitability classes.

\begin{tabular}{|c|c|c|c|c|}
\hline \multirow{2}{*}{$\begin{array}{l}\text { Establishment } \\
\text { of visceral } \\
\text { leishmaniasis }\end{array}$} & \multicolumn{2}{|c|}{ Pathogen requirements } & \multicolumn{2}{|c|}{ Vector requirements } \\
\hline & Coldest month & Warmest month & $\begin{array}{c}\text { Annual } \\
\text { mean temperature }\end{array}$ & Warmest month \\
\hline \multirow[t]{4}{*}{ 1) Excludable } & $<4^{\circ} \mathrm{C}$ & $<19^{\circ} \mathrm{C}$ & $<9^{\circ} \mathrm{C}$ & $<19^{\circ} \mathrm{C}$ \\
\hline & \multicolumn{2}{|c|}{ not fulfilled } & \multicolumn{2}{|c|}{ not fulfilled } \\
\hline & & & $<9^{\circ} \mathrm{C}$ & $\geq 20^{\circ} \mathrm{C}$ \\
\hline & & & \multicolumn{2}{|c|}{ partly fulfilled } \\
\hline \multirow[t]{6}{*}{ 2) Unlikely } & $<4{ }^{\circ} \mathrm{C}$ & $<19^{\circ} \mathrm{C}$ & $9^{\circ} \mathrm{C}$ & $\geq 20{ }^{\circ} \mathrm{C}$ \\
\hline & \multicolumn{2}{|c|}{ not fulfilled } & \multicolumn{2}{|c|}{ almost fulfilled } \\
\hline & $4{ }^{\circ} \mathrm{C}$ & $19^{\circ} \mathrm{C}$ & $<9^{\circ} \mathrm{C}$ & $\geq 20^{\circ} \mathrm{C}$ \\
\hline & \multicolumn{2}{|c|}{ partly fulfilled } & \multicolumn{2}{|c|}{ partly fulfilled } \\
\hline & & & $<9^{\circ} \mathrm{C}$ & $\geq 20^{\circ} \mathrm{C}$ \\
\hline & & & \multicolumn{2}{|c|}{ almost fulfilled } \\
\hline \multirow{4}{*}{$\begin{array}{l}\text { 3) Rather } \\
\text { unlikely }\end{array}$} & $<4^{\circ} \mathrm{C}$ & $\geq 20^{\circ} \mathrm{C}$ & $\geq 10^{\circ} \mathrm{C}$ & $\geq 20^{\circ} \mathrm{C}$ \\
\hline & \multicolumn{2}{|c|}{ partly fulfilled } & \multicolumn{2}{|c|}{ fulfilled } \\
\hline & $4{ }^{\circ} \mathrm{C}$ & $\geq 20{ }^{\circ} \mathrm{C}$ & $9{ }^{\circ} \mathrm{C}$ & $\geq 20{ }^{\circ} \mathrm{C}$ \\
\hline & \multicolumn{2}{|c|}{ almost fulfilled } & \multicolumn{2}{|c|}{ almost fulfilled } \\
\hline \multirow[t]{2}{*}{ 4) Possible } & $4{ }^{\circ} \mathrm{C}$ & $\geq 20^{\circ} \mathrm{C}$ & $9{ }^{\circ} \mathrm{C}$ & $\geq 20^{\circ} \mathrm{C}$ \\
\hline & \multicolumn{2}{|c|}{ almost fulfilled } & \multicolumn{2}{|c|}{ fulfilled } \\
\hline \multirow[t]{2}{*}{ 5) Likely } & $\geq 5^{\circ} \mathrm{C}$ & $\geq 20^{\circ} \mathrm{C}$ & $\geq 10^{\circ} \mathrm{C}$ & $\geq 20{ }^{\circ} \mathrm{C}$ \\
\hline & \multicolumn{2}{|c|}{ fulfilled } & \multicolumn{2}{|c|}{ fulfilled } \\
\hline
\end{tabular}

\section{Results}

Temperature-derived suitability for Phlebotomus species

Currently, the climate of south-west Germany almost satisfied the temperature demands of Phlebotomus spp. (Fig. 1). This spatial pattern corresponds with documented sandfly presence in the region (Naucke et al., 2008).

In this area of Germany, it is extremely likely that vector temperature constraint will be exceeded at some stage between 2011 and 2040. During this time period, vector requirements will also be fulfilled in some western (Cologne Bight) and eastern areas, depending on the prediction model.

During the mid-21 ${ }^{\text {st }}$ century, most parts of Germany can be expected to experience annual mean temperatures exceeding the lower threshold for sandfly establishment which is $10^{\circ} \mathrm{C}$. However, maximum summer temperatures of above $20^{\circ} \mathrm{C}$ will remain restricted to southern and eastern (continental) regions, and thus large areas of Germany may not be fully suitable for these insects until the end of the century. 
By the end of the $21^{\text {st }}$ century, many regions of Germany will have become suitable for phlebotomine sandflies, with only the Alps, low mountain ranges and northern areas not satisfying their thermal requirements.

Temperature-derived suitability for L. infantum complex

Temperature requirements of the pathogen will very likely not be achieved in Germany until the mid-21 $1^{\text {st }}$ century (Fig. 2). By then, it can be expected that the south-west will (nearly) experience suitable temperature conditions for pathogen prevalence, with some western regions also characterised by near-fulfilment of thermal suitability during this period. Eastern and south-eastern areas will achieve required summer but not winter temperatures, due to the projected gradient of decline in winter warming towards the east (Déqué et al., 2007; Jacob, 2008). Permanent establishment of the pathogen in eastern parts of Germany can be virtually excluded.
Surprisingly, by the end of $21^{\text {st }}$ the century some northern regions will provide higher suitability than the south-east. Large parts of the west of Germany and the Upper Rhine Valley in the south-west are projected to be warm enough for pathogen activity. According to these trends, western Germany seems to fulfil the climatic needs of the L. infantum complex earlier.

Temperature-derived establishment of visceral leishmaniasis

Due to the combined temperature constraints facing both vector and pathogen (Fig. 3), visceral leishmaniasis has been prevented from becoming endemic in Germany. As this is unlikely to change during the early $21^{\text {st }}$ century, the permanent occurrence of this infectious disease can be almost completely excluded during the next few years.

However by the mid-21 ${ }^{\text {st }}$ century, model projections detect small areas in the south and south-west as potential risk areas. These regions, offering suit-

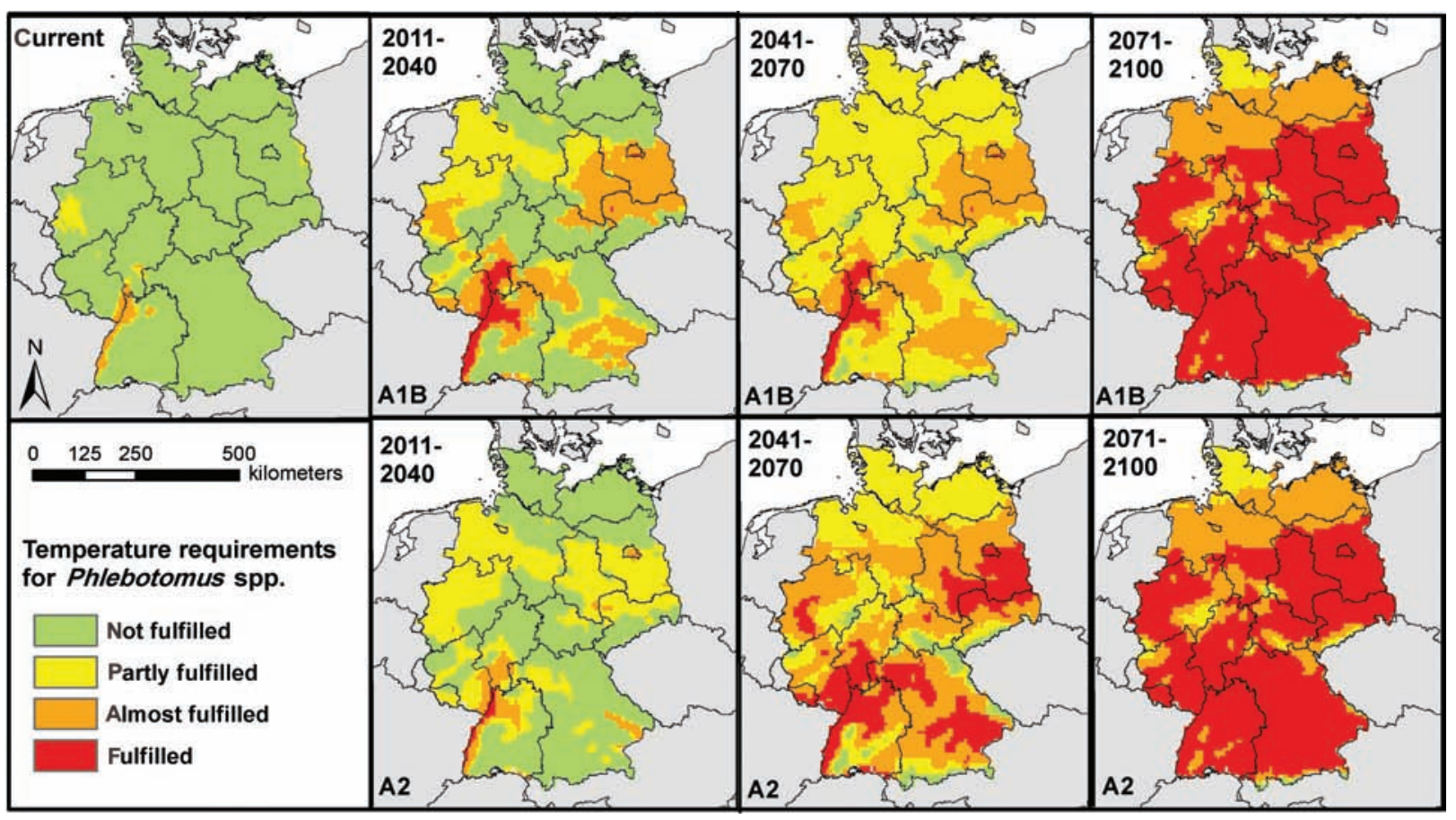

Fig. 1. Temperature-derived suitability for Phlebotomus spp. in Germany under current and projected temperature conditions represented by two IPCC climate change scenarios (A1B and A2). Calculations were based on 30-year average values. 


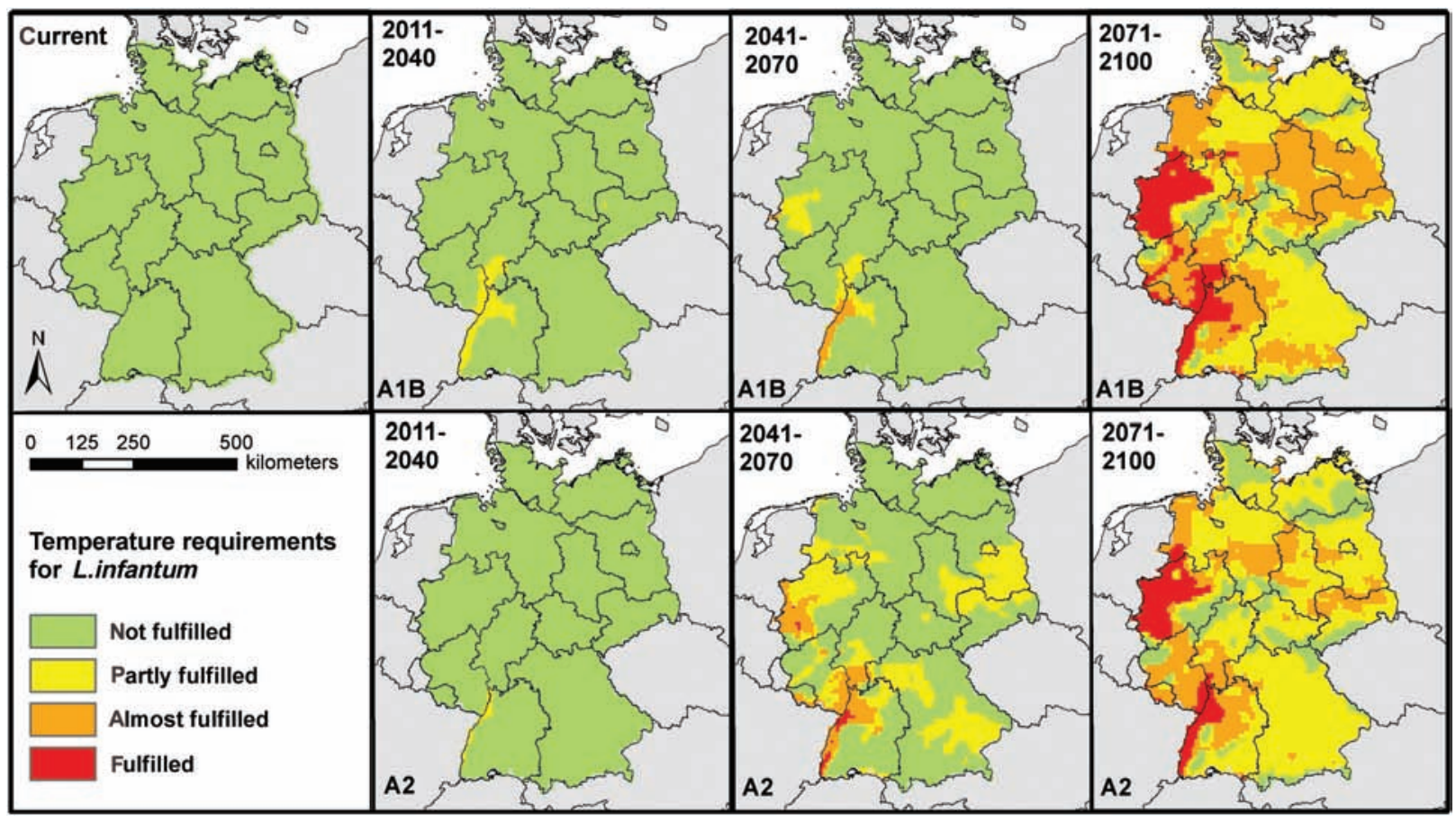

Fig. 2. Temperature-derived suitability for L. infantum complex in Germany under current and projected temperature conditions represented by two IPCC climate change scenarios (A1B and A2). Calculations were based on 30-year average values.

able thermal conditions for vector as well as for pathogen, may increase in extent by the end of the $21^{\text {st }}$ century. Regions where potential establishment seems to be completely implausible by the end of the $21^{\text {st }}$ century are the northernmost parts of Germany and the Alps in the south.

\section{Time-steps and scenarios}

Climatic simulations based on the A1B scenario yield higher temperatures for the first time period (2011-2040) than simulations of the A2 scenario. Consequently, some eastern areas will almost satisfy vector habitat requirements in the $\mathrm{A} 1 \mathrm{~B}$ projection but not in the A2 scenario. However in both scenarios, pathogen, and hence disease establishment, can be excluded during this period.

Remarkable differences in classification are projected for the second time period (2041-2070). Midcentury temperature conditions will permit disease establishment in western and south-western
Germany in the A2 scenario, while this will be rather unlikely under A1B conditions. The risk of establishment also differs for eastern Germany.

At the end of the century, both scenarios resemble each other more strongly with respect to vector, pathogen and consequently, disease requirements, than in the earlier periods. However some differences are still conspicuous. Areas providing climatic suitability will be fewer and more isolated - especially in the east - according to the $\mathrm{A} 2$ projection compared to the A1B scenario. Spatio-temporal variation in classification results for each scenario concerning the risk of temperature-derived establishment of visceral leishmaniasis are summarised in Table 2.

Increases in the risk of visceral leishmaniasis establishment vary significantly over time (Fig. 4). During the next few decades the potential threat increases faster in the A1B scenario than in A2, but by mid- $21^{\text {st }}$ century increases in risk become more apparent in the A2 projection. Generally, warming will be more rapid from the middle to the end of the 


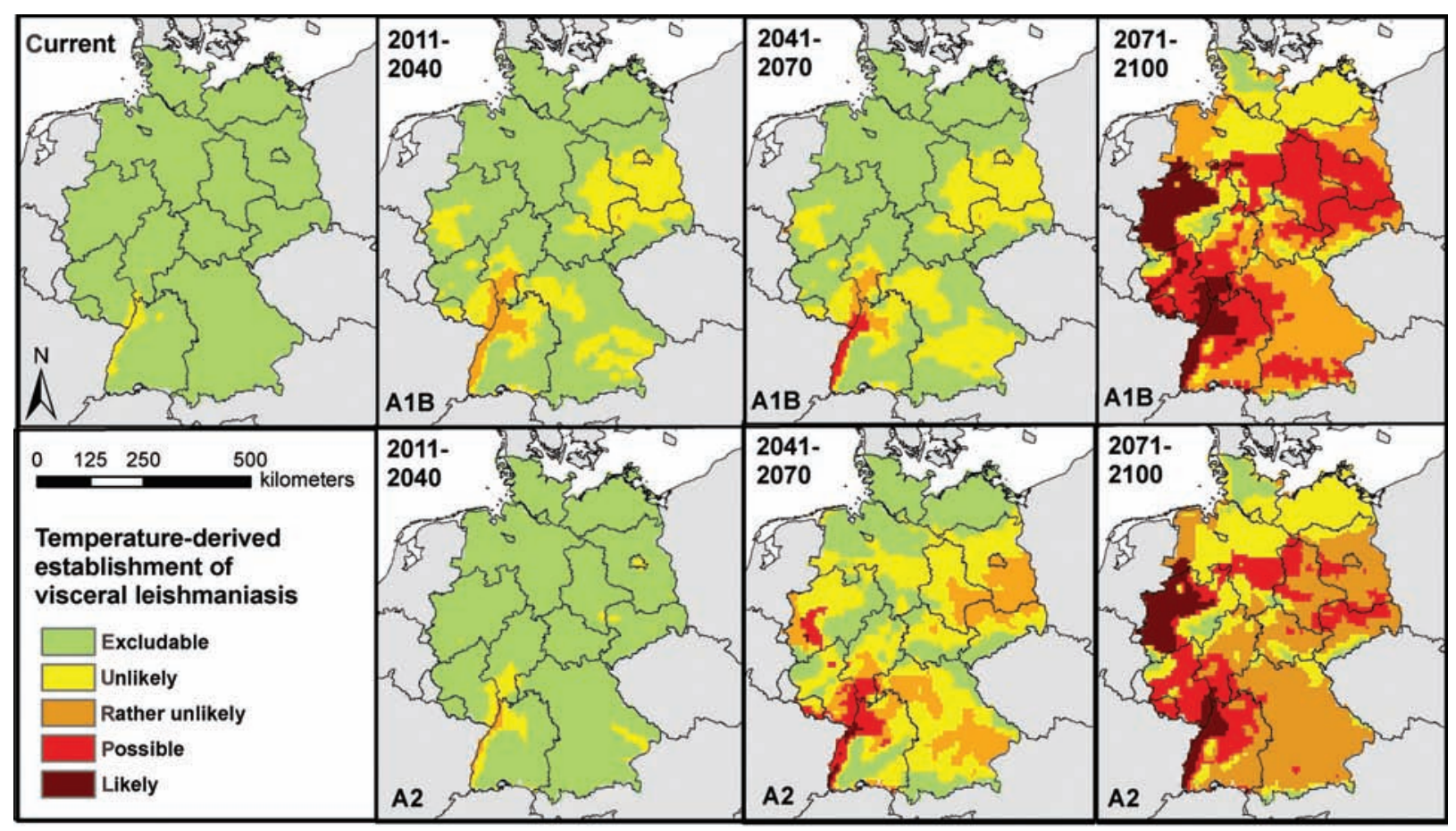

Fig. 3. Temperature-derived risk classes of visceral leishmaniasis in Germany under current and projected temperature conditions represented by two IPCC climate change scenarios (A1B and A2). Calculations were based on 30-year average values.

Table 2. Classified risk areas for potential autochthonous occurrence of visceral leishmaniasis. Risk areas are denoted as percentages of the total area of Germany separately for each time period and scenario. Regions at risk increase during the $21^{\text {st }}$ century in both scenarios.

\begin{tabular}{|c|c|c|c|c|c|c|c|}
\hline \multirow[t]{2}{*}{ Risk class } & \multirow[t]{2}{*}{ Current } & \multicolumn{2}{|c|}{ 2011-2040 } & \multicolumn{2}{|c|}{$2041-2070$} & \multicolumn{2}{|c|}{$2071-2100$} \\
\hline & & A1B & $\mathrm{A} 2$ & A1B & $\mathrm{A} 2$ & A1B & $\mathrm{A} 2$ \\
\hline 1) Excludable & 98.5 & 72.0 & 94.7 & 67.9 & 37.1 & 3.6 & 4.7 \\
\hline 2) Unlikely & 1.5 & 24.6 & 4.6 & 28.6 & 39.8 & 23.0 & 26.6 \\
\hline 3) Rather unlikely & - & 3.4 & 0.7 & 2.2 & 17.7 & 30.0 & 42.0 \\
\hline 4) Possible & - & - & - & 1.3 & 4.9 & 31.9 & 19.1 \\
\hline 5) Likely & - & - & - & - & 0.5 & 11.5 & 7.6 \\
\hline
\end{tabular}

$21^{\text {st }}$ century. Accordingly, transitions in risk class are highest within this period for both scenarios.

\section{Discussion}

In this study, potential effects of the expected change in European climate during the $21^{\text {st }}$ century on phlebotomine sandflies and visceral leishmania- sis are elucidated. During the $21^{\text {st }}$ century, temperature conditions will favour the occurrence of sandflies in Germany. Temperature requirements of the L. infantum complex will also be fulfilled, albeit with some delay, with thresholds for pathogen survival not expected to be surpassed before mid-century. Establishment of visceral leishmaniasis is therefore not predicted during the first half of the $21^{\text {st }}$ cen- 


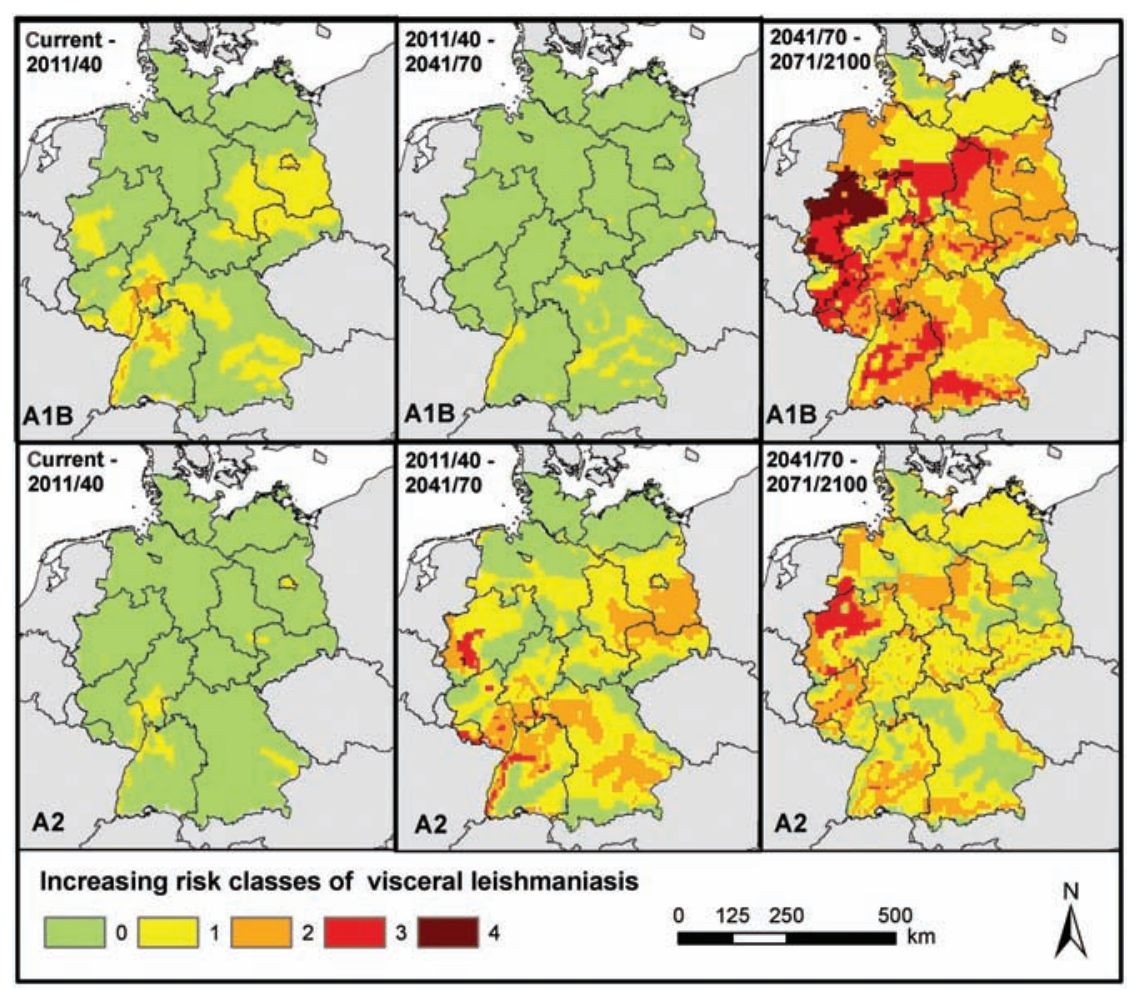

Fig. 4. Temporal variation in classification results for visceral leishmaniasis. Classified results for each time period (30-year averages) were subtracted from the following one for each scenario separately, in order to detect temporal trends in risk class variation.

tury. Afterwards, an increasing risk of infections is detected for Germany, where leishmaniasis does not presently occur. However, zones of elevated risk will be limited to certain regions.

The Upper Rhine Valley and Cologne Bight regions will be the first and most strongly exposed to this emerging biological risk according to two IPCC scenarios under consideration (A1B and A2). Nevertheless, the temporal dynamics of risk exposure vary between scenarios. Climate change projections are therefore associated with uncertainties. Even though two plausibe scenarios (IPCC, 2007) were chosen, it is not certain that either will occur, as they are still theoretical and based on a number of assumptions. This consequently leads to uncertainty when attempting to predict the establishment of vector-borne diseases.

We identified areas in the north-west of Germany which seem to become suitable for the pathogen earlier than those in the south-east (Bavaria). The former are characterised by maritime climatic conditions with mild winters due to the influence of the Gulf Stream, while the south-east is associated with a more continental climate typified by colder winters and strong seasonality.

Additionally, mountains in the south (e.g. Black Forest, Swabian Mountains) may restrict the eastward spread of vector and disease. Northern parts of Germany do not contain such barriers. In the east, risk of infections would rise during the projected increasingly hot summers. The important role of climate variability in the establishment of leishmaniasis has previously been pointed out by Cardenas et al. (2006) as well as Chaves and Pascual (2006).

Our analyses are based on the concordant tem- 
perature requirements of vector and pathogen. However, studies are currently limited to general constraints of the genus Phlebotomus and cannot, as yet, consider requirements at the species level. Knowledge regarding the specific temperature and moisture constraints regulating the presence of single Phlebotomus spp. is scarce. Phlebotomus spp. may differ subtly in their ecological requirements, particularly with regard to moisture and humidity (Lindgren and Naucke, 2008). Further studies are required in order to clarify the effects of climatic change on individual Phlebotomus spp.

Attention must also be concentrated on the variant transmission capacities of the species, with proof of the vector competence of Phlebotomus mascittii especially required (Naucke and Pesson, 2000).

The capacity of reservoir hosts is an additional factor affecting the permanent occurrence of a vector-borne disease. Approximations of the total number of leishmaniasis-infected dogs in Germany, which are mostly imported from the Mediterranean Region, range from 20,000 (Lozán et al., 2008) up to 150,000 (Harms-Zwingenberger and Bienzle, 2007). This constitutes an appreciable reservoir from which phlebotomine sandflies can gather pathogens in the detected risk zones.

There is currently no vaccine available against visceral leishmaniasis. The most efficient method of protection for humans and animals is to avoid sandfly bites - for instance via the use of insecticides (Maroli and Khoury, 2006). Surveillance and control of vectors and disease has proven difficult (Killick-Kendrick, 1999; Gramiccia and Gradoni, 2005). The introduction of potentially infected dogs must therefore be tightly monitored and restricted.

\section{Conclusion}

Leishmaniasis is not currently eminent in Germany, even if it does constitute a serious health hazard of increasing importance. We demonstrate here that the spread of a (sub-) tropical disease (i.e. visceral leishmaniasis) to previously non-endemic regions constitutes a risk in the $21^{\text {st }}$ century. We project differentiated spatial and temporal patterns for the probability of occurrence and local establishment of visceral leishmaniasis in Germany. Favourable regions for both vector and pathogen are situated close to unsuitable areas, with human mobility and transport links bridging these barriers between isolated habitats. However, vector dispersal ability, density of reservoir hosts and further environmental and anthropogenic factors must be better understood and included in future risk analyses. Feasible proactive adaptation strategies can then be implemented in order to delay or even avoid regional establishment of vector-borne diseases.

\section{Acknowledgements}

The authors would like to thank the Bavarian State Ministry for the Environment and Public Health for the grant. Furthermore, the Bavarian Health and Food Safety Authority, coordinating the cooperative project "Vectorborne infectious diseases in climate change investigations VICCI-study" was of additional help. Two reviewers gave valuable comments on an earlier version of the manuscript.

\section{References}

Aspoeck H, 2008. Postglacial formation and fluctuations of the biodiversity of Central Europe in the light of climate change. Parasitol Res 103, 7-10.

Aspoeck H, Gerersforfer T, Formayer H, Walochnik J, 2008. Sandflies and sandfly-borne infections of humans in Central Europe in the light of climate change. Wien Klin Wochenschr 120, 24-29.

Aspoeck H, Walochnik J, Gerersforfer T, Formayer H, 2007. Risiko-Profil für das autochthone Auftreten von Leishmaniosen in Österrreich - StartClim 2006, 49 pp. Available online: www.austroclim.at/startclim (accessed: April, 2010).

Bogdan C, Schonian G, Banuls AL, Hide M, Pratlong F, Lorenz E, Rollinghoff M, Mertens R, 2001. Visceral leishmaniasis in a German child who had never entered a known endemic area: case report and review of the literature. Clin Infect Dis 32, 302-306. 
Camargo LB, Langoni H, 2006. Impact of leishmaniasis on public health. J Venom Anim Toxins Trop Dis 12, 527-548.

Cardenas R, Sandoval CM, Rodriguez-Morales AJ, FrancoParedes C, 2006. Impact of climate variability in the occurrence of leishmaniasis in Northeastern Colombia. Am J Trop Med Hyg 75, 273-277.

Chamaille L, Tran A, Meunier A, Bourdoiseau G, Ready P, Dedet JP, 2010. Environmental risk mapping of canine leishmaniasis in France. Parasite Vectors 3, 31.

Chaves LF, Pascual M, 2006. Climate cycles and forecasts of cutaneous leishmaniasis, a nonstationary vector-borne disease. PLoS Med 3, 1320-1328.

Cross ER, Hyams KC, 1996. The potential effect of global warming on the geographic and seasonal distribution of Phlebotomus papatasi in Southwest Asia. Environ Health Perspect 104, 724-727.

Déqué M, Rowell DP, Luthi D, Giorgi F, Christensen JH, Rockel B, Jacob D, Kjellstrom E, de Castro M, van den Hurk B, 2007. An intercomparison of regional climate simulations for Europe: assessing uncertainties in model projections. Clim Change 81, 53-70.

Dujardin J-C, Campino L, Canavate C, Dete J-P, Gradoni L, Soteriadou K, Mazeris A, Ozbel Y, Boelaert M, 2008. Spread of vector-borne diseases and neglect of leishmaniasis, Europe. Emerg Infect Dis 14, 1013-1018.

Fischer D, Stahlmann R, Thomas S, Beierkuhnlein C, 2009. Global warming and exotic insect borne diseases in Germany: novel threats and scenarios. Geographische Rundschau (international edition) 5, 32-38.

Fischer D, Thomas S, Beierkuhnlein C, 2010. Climate change effects on vector-borne diseases in Europe. Nova Acta Leopoldina 384, 99-107.

Gramiccia M, Gradoni L, 2005. The current status of zoonotic leishmaniases and approaches to disease control. Int J Parasitol 35, 1169-1180.

Harms G, Schonian G, Feldmeier H, 2003. Leishmaniasis in Germany. Emerg Infect Dis 9, 872-875.

Harms-Zwingenberger G, Bienzle U, 2007. Nach Deutschland importierte Leishmaniosen. Dtsch Ärztebl 104, 3108-3113.

Hijmans RJ, Cameron SE, Parra JL, Jones PG, Jarvis A, 2005. Very high resolution interpolated climate surfaces for global land areas. Int J Climatol 25, 1965-1978.

IPCC, 2007. Climate Change 2007: Synthesis Report, 52 pp.
Intergovernamental Panel on Climate Change; available online: http://www.ipcc.ch/pdf/assessment-report/ar4/syr/ ar4_syr.pdf (accessed: June, 2010).

Jacob D, 2008. Short communication on regional climate change scenarios and their possible use for impact studies on vector-borne diseases. Parasitol Res 103, 3-6.

Jentsch A, Beierkuhnlein C, 2008. Research frontiers in climate change: effects of extreme meteorological events on ecosystems. C R Geosci 340, 621-628.

Killick-Kendrick R, 1999. The biology and control of phlebotomine sand flies. Clin Dermatol 17, 279-289.

Killick-Kendrick R, Killick-Kendrick M, 1987. The laboratory colonization of Phlebotomus ariasi (Diptera, Psychodidae). Ann Parasitol Hum Comp 62, 354-356.

Kuhn KG, 1999. Global warming and leishmaniasis in Italy. Trop Med Int Health 7, 1-2.

Lindgren E, Naucke T, 2008. Leishmaniasis: influences of climate and climate change, epidemiology, ecology and adaptation measures. In: Menne B and Ebi KL (eds). Climate change and adaptation strategies for human health. Darmstadt, Germany, 131-156.

Lozán JL, Garms R, Naucke T, 2008. Die Leishmaniose - eine potenzielle Gefahr in Mitteleuropa. In: Lozán JL et al. (eds): Warnsignal Klima: Gesundheitsrisiken. Hamburg, Germany, 211-214.

Maroli M, Khoury C, 2006. Current approaches to the prevention and control of leishmaniasis vectors. Vet Res Commun 30, 49-52.

Maroli M, Rossi L, Baldelli R, Capelli G, Ferroglio E, Genchi C, Gramiccia M, Mortarino M, Pietrobelli M, Gradoni L, 2008. The northward spread of leishmaniasis in Italy: evidence from retrospective and ongoing studies on the canine reservoir and phlebotomine vectors. Trop Med Int Health 13, 256-264.

Naucke T, 2007. Leishmaniasis - entering Germany. Tierarztl Umsch 62, 495-500.

Naucke T, Menn B, Massberg D, Lorentz S, 2008. Sandflies and leishmaniasis in Germany. Parasitol Res 103, 65-68.

Naucke T, Pesson B, 2000. Presence of Phlebotomus (Transphlebotomus) mascittii Grassi, 1908 (Diptera: Psychodidae) in Germany. Parasitol Res 86, 335-336.

Neuber H, 2008. Leishmaniasis. J Dtsch Dermatol Ges 6, 754-765.

Nieto P, Malone JB, Bavia ME, 2006. Ecological niche model- 
ing for visceral leishmaniasis in the state of Bahia, Brazil, using genetic algorithm for rule-set prediction and growing degree day-water budget analysis. Geospat Health 1, 115-126.

Patz JA, Campbell-Lendrum D, Holloway T, Foley JA, 2005. Impact of regional climate change on human health. Nature 438, 310-317.

Peterson AT, Shaw J, 2003. Lutzomyia vectors for cutaneous leishmaniasis in southern Brazil: ecological niche models, predicted geographic distributions, and climate change effects. Int J Parasitol 33, 919-933.

Ready PD, 2008. Leishmaniasis emergence and climate change. Rev Sci Tech Off Int Epizoot 27, 399-412.

Reithinger R, Dujardin J-C, 2007. Molecular diagnosis of leishmaniasis: current status and future applications. J Clin Microbiol 45, 21-25.

Rossi E, Rinaldi L, Musella V, Veneziano V, Carbone S, Gradoni L, Cringoli G, Maroli M, 2007. Mapping the main
Leishmania phlebotomine vector in the endemic focus of the Mt. Vesuvius in southern Italy. Geospat Health 1, 191-198. Shaw J, 2007. The leishmaniases - survival and expansion in a changing world. A mini-review. Mem Inst Oswaldo Cruz 102, 541-547.

Shope R, 1991. Global climate change and infectious diseases. Environ Health Perspect 96, 171-174.

Sutherst RW, 2004. Global change and human vulnerability to vector-borne diseases. Clin Microbiol Rev 17, 136-173.

Weitzel T, Muhlberger N, Jelinek T, Schunk M, Ehrhardt S, Bogdan C, Arasteh K, Schneider T, Kern WV, Fatkenheuer G, Boecken G, Zoller T, Probst M, Peters M, Weinke T, Gfrorer S, Klinker H, Holthoff-Stich ML, 2005. Imported leishmaniasis in Germany 2001-2004: data of the SIMPID surveillance network. Eur J Clin Microbiol Infect Dis 24, 471-476.

WHO, 1984. The leishmaniases: report of an expert committee. WHO Tech Rep Ser 701, 1-140. 